\title{
Processing PRESUPPOSITIONS. ARE IMPLICATIVE VERBS SOFT TRIGGERS? ${ }^{1}$
}

\author{
MATEUSZ WLODARCZYK \\ University of Szczecin, Szczecin, Poland \\ mateusz.wlodarczyk@usz.edu.pl
}

\begin{abstract}
This paper investigates the question whether implicative verbs should be considered as soft presupposition triggers, i.e., as triggers activating optional context repairs. I present the results of an experiment in which test subjects were asked to read short dialogues containing either presupposition triggers or conversational implicatures and, next, answer the questions regarding the information communicated on the level of presupposition or implicatures, respectively. The results of within-subject ANOVA show that presuppositions activated by the use of implicative verbs are significantly less accessible and illicit significantly longer response times than presuppositions activated by the use of hard triggers, suggesting that they can be classified as soft presupposition triggers. The obtained results also show that presuppositions activated by the use of different triggers are heterogenous in regards to the accessibility of information.
\end{abstract}

Keywords: conversational implicature, implicative verbs, presuppositions

\section{Introduction}

In recent years, we have seen an increasing number of experimental research on presuppositions. (Tiemann et. al. 2011; Tiemann et al. 2015 Schwarz 2015; Domaneschi 2016; Domaneschi and Di Paola 2017) Most of this research concentrates on a few typical cases of presupposition triggers: definite descriptions, factive verbs, and change of state verbs. In addition, most of the experimental studies on presuppositions do not allow for other pragmatic phenomena, such as speech acts or conversational implicatures, which makes intercategorical comparisons of the processing of different pragmatic aspects of meaning difficult. In this paper, I present the results of an experiment that focuses on presuppositions triggered by the use of implicative verbs, the category of triggers which has not been yet extensively studied. The primary goal of the experiment was to gather evidence relevant to the question of whether implicative verbs could be classified as soft presupposition triggers. According to Glanzberg

\footnotetext{
${ }^{1}$ This research is supported by the National Science Centre, Poland, through research grant No.
} 2015/19/B/HS1/03306. 
(2003, 2005), presuppositions associated with the use of soft triggers do not result in obligatory context repair in situations when the context does not satisfy the presupposition. By testing whether presuppositions activated by the use of different triggers are accommodated, which I understand as a context-repair mechanism (Witek 2019), we may determine whether they are hard or soft triggers.

The paper consists of four sections. In the first part, I briefly characterise presuppositions as linguistic phenomena; I also provide a brief survey of the literature on implicative verbs. In the second part, I describe current empirical approaches to the study of presuppositions. In the third part, I present the experimental design and results and, in the fourth part, a discussion of the outcome.

\section{Presuppositions}

The presupposition of an utterance can be broadly understood as background information that is taken for granted by the interlocutors and relative to which the utterance is to be interpreted and evaluated (Beaver and Geurts 2014). However, the precise definition of this notion depends on the theoretical model we have decided to adopt. In semantical models dating back to Frege (1892) and Strawson (1950), the presupposition of a sentence is defined in terms of necessary requirements that have to be met in order for the sentence to be truth-evaluable: If the presupposition of a sentence is false, then the sentence lacks a truth value. Pragmatic models of presuppositions (Stalnaker 1974, 1998, 2002) take a different route. Firstly, on their ground, presuppositions are not properties of sentences; rather, presupposing is what the speaker does while uttering a sentence. Secondly, they are understood in terms of felicity conditions. When a speaker performs a speech act that activates a presupposition which is satisfied by the common ground of the conversation, then the speech act in question is infelicitous (von Fintel 2006).

Independently of whether we accept the pragmatic or semantic approach to presuppositions, we can speak of three characteristic features of the phenomena in question. Firstly, presuppositions tend to survive in $S$-family sentences; that is, they are preserved when the relevant sentence is embedded under the scope of negation, modal verbs and other entailment-cancelling operators (Domaneschi 2016).. Secondly, they are assumed to be marked by the speaker's use of specific lexical elements or syntactic constructions, called presupposition triggers (Beaver and Geurts 2014). One of the earliest lists of triggers comes from Levinson (1983: 181-184), who enumerated 13 different presupposition-triggering constructions. Levinson claims that his list contains paradigmatic cases of presuppositions, but he also acknowledges that it may be incomplete (1983: 184). However, in recent years, the inclusion of some of the entries on the list have been contested, as researchers (Abbott 2000, Karttunen 2016) suggest that some Levinsonian triggers should be treated in terms of different kinds of pragmatic phenomena. We 
will discuss some of those objections in later sections. Thirdly, in case of presupposition failure it's content can be accommodated by the hearer; as we already know, according to the pragmatic model, an utterance whose presuppositions are not part of the common ground between a speaker and her interlocutors is assumed to be infelicitous. However, in everyday conversations, if there is no specific reason to refrain from doing it, a hearer can just update the common ground with the information that is on the level of the presupposition. The discursive mechanism of accommodation responsible for this kind of contextrepair was first described by David Lewis (1979). This shows that presuppositions in certain context can perform an informative role; they can update the common ground just as assertions do. The notion of accommodation is a very convenient tool for experimental research on presuppositions: by creating experimental settings in which test subjects must accommodate presuppositions activated by different utterances, researchers can explore whether presuppositional content of given utterance have been processed.

\subsection{Homogeneity of presupposition triggers}

Although in the initial period of research on presuppositions they were treated as if they comprised a more or less uniform category, more recent theoretical approaches allow for apparent differences between pragmatic implications associated with the use of different presupposition triggers. For instance, some scholars (Abusch 2002, 2010; Jayez et al. 2015) draw a distinction between soft and hard presupposition triggers. According to Dorit Abusch, the main difference between those two categories is that the latter activate semantic presuppositions, while the former activate pragmatic presuppositions, which are weaker and context-dependent. Michael Glanzberg (2003, 2005), by contrast, develops an alternative account of hard and soft presupposition triggers, basing his analysis on the notion of felicity conditions mentioned in section 1. As noted, the presupposition of a sentence or of the act made in its uttering can be understood as the requirements that the sentence or utterance places upon the context in which it appears in order for the use of the sentence to be felicitous (Glanzberg 2003). The presuppositional requirement of an act made in uttering sentence s in context $\mathrm{c}$, then, can be defined as a relation holding between sentence s, which contains a presupposition trigger, context $\mathrm{c}$ and presupposed proposition $\mathrm{p}$ such that for $\mathrm{s}$ to be felicitous in c, c must entail p. The difference between soft and hard presupposition triggers becomes evident when we consider what happens when the felicity conditions of a sentence containing the presupposition trigger under scrutiny are not met. In standard cases, this problem can be resolved by various context-repair processes; for example, accommodation (described in section 1) or 'repair-to-negation' (described below). However, as Glanzberg observes, such context-repairing processes - accommodation and others - are not obligatory in all cases. Namely, they are not mandatory when the presuppositions under scrutiny are activated by a subclass of triggers which he identifies as soft 
presupposition triggers. Therefore, we can define hard presupposition triggers as triggers whose use in presupposing utterances gives rise to obligatory contextrepairs, whereas soft presupposition triggers induce optional context-repairs.

Glanzberg proposes two tests for identifying soft and hard presupposition triggers: the indirect speech act test, in which we ask the speaker to make a truthvalue judgement of a sentence by giving a yes-no answer; and the echo-assessment test, where we not only ask speakers to make truth-value assessments of sentences containing presupposition triggers, but also instruct them to to do so by using exactly the same words that are employed to form the assessed assertions. For example, in asking a speaker to assess the truth-value of the sentence presented in $1 \mathrm{a}$, we expect him to produce an echoing response in the form of $1 \mathrm{~b}$ :

a. Was Alan Shepard the first man on the Moon?

b. No, Alan Shepard was not the first man on the Moon

In such cases, the speaker should not have a problem giving (1b) as the answer to the question posed in (1a). This suggests that no context repair is necessary. However, the situation is different when we test definite descriptions using echoassessment:

a. Is the king of France coming to visit us?

b. \# The king of France is not coming to visit us.

c. The king of France is NOT coming to visit us - there is no King of France!

d. Er .... no. There is no King of France.

As Glanzberg suggests, the speaker will not give the answer presented in (2b), which would constitute a clear truth-value judgement. Instead, she will try to repair the context by either giving (2c) - which we can call 'repair by presupposition cancelling negation' (in which the negative answer is given with the right intonation pattern, with a stress on negation) or (2d), which we can call 'repair-to-negation' (Glanzberg 2003; 2005). We see that the echo-assessment test forces the speaker to reproduce the defective sentence. In cases of sentences whose presuppositions are not satisfied by context, the speaker will not do this. Instead, she will try to go around the problem by initiating the repair.

Now let us assume that (3a) is uttered in a context in which the fact that it was unlikely or unexpected for John to solve the problem is not part of the common ground (Glanzberg 2003):
a. Even John solved the problem?
b. Yes, even John solved the problem... but why did you say 'even'?
c. \# That's NOT SO. He would have solved it if anyone did. 
The speaker will utter (3b), which is a truth-value judgment. Repair here is optional, and repair strategies that were available to the speaker in (2) would generate infelicity if applied to the current case-i.e., if employed to utter (3c).

In the next step, using the framework of the context-change semantics, Glanzberg develops a formal notation to capture the difference between the two categories of triggers. ${ }^{2} \mathrm{He}$ introduces the operator " $\downarrow$ " as a specific case of update instruction - a test - which can be understood as an instruction to check whether a function holds. If it holds, proceed; otherwise, the computation fails. Notice that on the pragmatic account, presuppositions are understood as certain conditions placed by the felicity of an utterance on the context of its production. Therefore, Glanzberg proposes that they can be formalized in the context change semantics as a test performed on a context:

$$
c[\downarrow x(x=p)]=\left\{\begin{array}{c}
c \text { if } c \subseteq p \\
\text { fail otherwise }
\end{array}\right.
$$

Informally, we can say that the update instruction here is as follows: Check whether context $c$ contains proposition $p$. If it does, proceed. If it does not, then computation fails. Notice that the test itself does not in any way modify the context; it only checks if the context is constituted in a certain way; and if it is not the case that, for example, $p$ is in the context, it gives a fail state as output. By constructing different update instructions using operator $\downarrow$, we can distinguish between hard and soft presupposition triggers. Let us consider an utterance containing a factive verb, which Glanzberg classifies as a hard presupposition trigger:

(4) John regrets fighting with the evil sorcerer.

Verb 'regret' presupposes the truth of the complement sentence. Additionally, 'regret' has an attitudinal component: John has a certain negative propositional attitude towards whatever the complement sentence expresses. The update instruction has the following form:

i) $c[\downarrow x(x=p)][R(j, x)]$

Informally, we can say that the instruction here is: check the context to determine whether it contains proposition $p$, and update the context with the information 'John is regretful about $p$ '. We see that if the first part of the instruction (check whether the context contains $p$ ) results in fail, the second part cannot be performed, since the occurrence of $x$ in the second instruction is bound by $\downarrow$. Notice that this formalisation captures the essential characteristic of hard

2 We only provide a general overview of this notation to elucidate the fact that soft presupposition triggers only induce optional repairs. For a more in-depth description, see Glanzberg 2003. 
presupposition triggers: If the context is not constituted in a certain way, we have a case of expression failure, and context repair must occur.

Let us now consider a soft presupposition trigger:

(5) Even John solved the problem.

The focus-sensitive particle "even" in (5) triggers the presupposition that it was not expected for John to solve the problem and that someone other than John also solved the problem. Focus-sensitive particles are assumed to be soft presupposition triggers; that is, they only induce optional context repair, as we have seen in (3). The update instruction here could have the following form:

ii) $c[\downarrow x(x=p)][S(j)]$

Informally, the instruction is: Check the context to determine whether it contains proposition $p$, and update the instruction with the information "John solved the problem." The second part of the instruction does not contain a variable bound by the operator $\downarrow$; therefore, it can be carried out even if the first part gives us a fail state. Following Glanzberg, we can say:

The result of processing the first instruction is a fail state. There is a natural discourse strategy to apply in such a case. Reset to the prior information state, and try to go on to process the rest of the discourse. This is especially natural for failed $\downarrow$-instructions, as if our check of the context fails, we might still try to see what we were to do with it. With [(5)], this works perfectly well. After resetting the context after the failed $\downarrow$, we can perfectly easily process $[R(j)]$, updating to only worlds in which John solved the problem. We have an infelicity, as there was a fault in our update computation. But it is an infelicity we can work around in processing the utterance, and no further repair is required. We have optional repair, and a weak presupposition. (Glanzberg 2003)

Glanzberg's notion of hard and soft presupposition triggers might be useful for making empirical predictions. Hard presupposition triggers place a strict demand on the hearer: If the felicity conditions of an utterance are not satisfied, then its context, in order to avoid expression failure, must be repaired. As we already know, accommodation is one of the mechanisms by which the hearer can repair the context. Therefore, we might hypothesize that in cases of hard presupposition triggers (assuming there are no factors blocking the process), a hearer will be hardpressed to accommodate presupposed content. Conversely, with soft presupposition triggers, where the repair is optional, the hearer may opt-out of accommodation - for example, if cognitive demands are too high. It is worth noting that Glanzberg's echo-assessment test and indirect speech act test are constructed in such a way that the accommodation of the presupposed content is blocked. Therefore, the hearer has to rely on different strategies to repair the context. However, if accommodation is available as a repair strategy, it should still only be optional, not mandatory, in the case of soft triggers. The reason is, 
once again, that the assertive component of a sentence containing a soft presupposition trigger can be used to update the context regardless of the outcome of the $\downarrow$ operator. Accommodation, then, is not necessary for an utterance containing a soft trigger to be used for a context update. In fact, following Domaneschi 2016, we could say that the hearer does not have to even process the content of the presupposition.

The distinction between hard and soft presupposition triggers, as well as other observable differences in the behavior of presuppositions, may suggest that despite similar general features, presuppositions activated by various triggers might have different sources. This suggestion is made by Mandy Simons (2013) and later developed by Beaver et al. (2017) within the framework of the Question Under Discussion (QUD) model of communication. In her 2013 paper, Simons points out that most of the theoretical research on presuppositions concentrates on the projection problem, and there are very few attempts to answer the question, "How do presuppositions arise?" (For a discussion of this issue see Witek 2019). According to Simons, despite the considerable support for the view that presuppositions have conventional sources, there are at least two reasons to consider a conversational basis for at least some presuppositions. The first reason is contextual defeasibility: In explicit ignorance contexts, where it is known that the speaker uttering a sentence with a presupposition trigger does not know whether the presupposition is true or false, the presupposition does not arise. The second reason is non-detachability: Similarly to conversational implicatures, some presuppositions are activated not by specific linguistic forms but, rather, by the semantic content of certain lexical elements. Simons proposes that those presuppositions do not have conventional sources, but are inferences derived from a general conversational Interpretation principle (Simons 2013: 342):

Suppose that $\mathrm{P}$ entails but is not entailed by $\mathrm{Q}$. A speaker who raises the question whether

$\mathrm{P}$ indicates a belief that $\mathrm{Q}$ is true.

$\mathrm{Q}$ here is a presupposition activated by raising question whether P. If I am raising the question whether $\mathrm{P}$ - and Simons argues that giving an answer to a question is also way to raise it (Simons 2013: 341) - I am conversationally indicating that $\mathrm{I}$ believe that $\mathrm{Q}$ (presupposition of $\mathrm{P}$ ) is true. This is due to the fact that it would be hard for anyone to think that $\mathrm{I}$ can raise the question whether $\mathrm{P}$ without believing that $\mathrm{Q}$ is true. Therefore, on Simons account, the derivation of presuppositions is akin to the mechanism underlying the functioning of conversational implicatures. The assumption that some presupposition triggers can have conversational sources might be used to explain the differences between soft and hard presupposition triggers.

Lastly, Lauri Karttunen (2016) argues that the current treatment of presuppositions as constituting a uniform class of phenomena is a mistake that results from the "hunt" for presupposition triggers that occurred in late 1960s and early 1970s. He states: 
The error, from which the field still has not completely recovered, was the idea that the items on this list exemplify the same phenomenon. The zoo of presupposition triggers should have been constructed with separate cages for different species. The quest for a unified theory of presupposition, pragmatic or semantic, has been a failure. (Karttunen 2016: 706-707)

Karttunen goes on to suggest that different triggers can be related to different linguistic phenomena described by Frege: Voraussetzung (presuppositions); Andeutung ("hinting"), which he identifies as Grice's "conventional implicature"; and Nebengedanke ("subsidiary thought"), which he likens to what Geis and Zwicky (1971) call "invited inference."

The aim of this section was to illustrate that despite the initial attempts to treat presuppositions as forming a homogenous category, there is ample evidence suggesting that this homogeneity is illusory. Although we can point to some common features (such as preservation under negation), there are also features that are specific to particular triggers (or groups of triggers). Additionally, I presented a distinction between soft and hard presupposition triggers. Following Glanzberg, I defined hard presupposition triggers as expressions or constructions whose use in a presupposing utterance leads to obligatory repairs in cases of presupposition failure; consequently, I take soft presupposition triggers to be expressions or constructions that motivate optional repairs in cases of presupposition failure. In the next section, I take a closer look at presuppositions triggered by implicative verbs that seem to constitute a peculiar class of pragmatic implications calling for specific explanation.

\subsection{Implicative verbs}

Implicative verbs were first described by Lauri Karttunen (1971), who contrasted them with a different category of presupposition triggers: factive verbs. A sentence (or its utterance) whose main verb is factive presupposes the truth of its complement sentence. For example both (6a) and (6b) presuppose (6c):
a. John knows that the incident happened.
b. John doesn't know that the incident happened.
c. The incident happened.

With implicative verbs, the situation is quite different. While an asserted sentence with an implicative verb as a predicate commits the speaker to an implied proposition which consists of a complement sentence, negation of the main sentence does not carry this implication. In other words, this implication doesn't project over the negation and, in this connection, cannot be considered a presupposition of implicative verbs. Looking at the following example, while (7a) implies the truth of (7c), (7b) does not. 

a. John managed to stop the evil sorcerer.
b. John didn't manage to stop the evil sorcerer.
c. John stopped the evil sorcerer's plan.

However, in the above example, something does project - namely the assumption that in the situations described by (7a) and (7b), James at least made an attempt to stop the evil sorcerer's plan. Intuitively, we feel that without this assumption, both (7a) and (7b) should not be regarded as true (Karttunen 1971: $344)$. So the presupposition for (7a) and (7b) is:

d. John tried to stop the evil sorcerer's plan.

Karttunen tentatively defines the presuppositions of implicative verbs as some sufficient and necessary condition for the events described by their complement clauses. One interesting aspect of implicative verbs is the exact presuppositional content triggered by different verbs that fall into this category. The presupposed content activated by the use of other categories of triggers is the same for all of the lexical elements that fall into that category. For example, while we have different factive verbs, each and every one of them presupposes the truth of the complement of the sentence of which it is a predicate. The situation is different with implicative verbs. While they share the same general presupposition of some necessary and sufficient condition for the event described in their complement, the condition in question is different for each implicative verb. For example, as we saw earlier, the presupposition for $X$ managed to do $Y$ is $X$ tried to do $Y$. For a different implicative verb construction, e.g., $X$ remembered to do $Y$, its presupposition is $X$ ought to do $Y$. According to Karttunen then, each implicative verb activates the presupposition as sufficient and necessary condition which is specific for each verb. Another interesting aspect of implicative verbs to which I allude elsewhere (Włodarczyk 2018) is the representation of their presuppositional content at the lexical level of a sentence. Let us once again compare implicative verbs and factive verbs. In sentences containing factive verbs, the content of their presuppositions is lexically encoded by their complement sentences, as is clearly demonstrated in (6). The phrase "the incident happened," which in this case is the presupposed content, is present both in (6a) and (6b). By contrast, what is presupposed by sentences within which implicative verbs occur is not represented lexically. For instance, proposition (7d), which is presupposed by (7a) and (7b), is represented by no syntactically independent segment of these sentences, since it contains the verb "tried" that occurs in neither (7a) nor (7b).

Using Glanzberg's echo-assessement test presented in section 1.1, we can check whether presuppositions should be considered either as soft or hard presupposition triggers. Consider, for instance, a situation in which John closed the door but the proposition that he was obligated to do it is not the part of the common ground: 
a. Did John remember to close the door?

b. Yes, John remembered to close to door... but in fact he wasn't the one asked to close the door

c. \# That's not so! He wasn't obligated to close the door!

It's hard to imagine that a speaker would say (8c). Rather, she is naturally expected to use (8b) to express her truth-value judgement and initiate optional repair - in this case, not by the means of accommodation, but by negation of the presupposition. Therefore, according to the test devised by Glanzberg, the presupposition associated with the use of the verb 'remember' could be considered a soft presupposition trigger. Finally, it is worth noting that both Barbara Abbott (2000) and Lauri Karttunen (2016) have separately suggested that implicative verbs are better understood as activating conventional implicatures rather than presuppositions; also, presuppositions activated by the use of implicative verbs are reinforceable, in contrast to other presupposition triggers, and can potentially be treated as soft presupposition triggers. I elaborate on these issues in section 2.2.

\section{Presuppositions in experimental pragmatics}

For most of the $20^{\text {th }}$ century, pragmatics was primarily a purely theoretical endeavor. This started to change in the 80's due to the emergence of cognitive pragmatics, which in turn led to the application of experimental methods developed in cognitive psychology to assess the plausibility of theoretical models of language use (Domaneschi 2016). As Dan Sperber and Ira Noveck (2007: 2-3) observe, there is a greater need for experimental data in pragmatics than in semantics; the reason is that our semantic intuitions are, in fact, semantic facts, while pragmatic intuitions are about how utterances would be interpreted in specific contexts and by specific listeners. Experimental data are therefore needed to establish how these interpretative processes occur in real-life situations. Experimental pragmatics is mainly interested in the times and phases of different pragmatic processes; in the past decade, most of the research in this area has been primarily focused on the processing of figurative language and scalar implicatures (Domaneschi, 2016). Research on presuppositions has been scarce in comparison to other topics in experimental pragmatics. However, recent publications (Tiemann et. al. 2011; Schwarz 2015; Domaneschi 2016; Domaneschi and Di Paola 2017) that focus exclusively on experimental work indicate an upsurge in research on presuppositions.

As experimental research on presuppositions is relatively young, a proper methodology is still being developed; however, we can observe an emergence of certain standard procedures. In order to gather on-line data - the data about processes involved in understanding a presupposition while the presupposing utterance unfolds - researchers most often use self-paced reading tasks (Tiemann 
et. al 2011; 2015, Domaneschi and Di Paola 2017). In order to gather off-line data about how presuppositional content is inserted and recovered in the mental model of the discourse, researchers use the verification procedure of asking direct questions about the presuppositional content of utterances with informative presuppositions - that is, in situations where it is assumed that accommodation should take place. To provide a more in-depth description of the procedures used to study presuppositions, and to provide the motivation for the experiment presented in section 3 of this paper, I now describe two experiments on presuppositions. Firstly, I describe Domaneschi's (2016) experiment on the processing of soft and hard presupposition triggers; secondly, I present an experiment on the reinforceability of presupposition triggers (Włodarczyk 2019). While the results of the Domaneschi's experiment support Glanzberg's distinction between soft and hard triggers, the results of the reinforceability experiment show that implicative verbs, contrary to other presupposition triggers, can be reinforced without inducing anomalous redundancies.

\subsection{Processing of presupposition}

Domaneschi (2016) used an off-line self-paced reading task to test Glanzberg's account of soft and hard presupposition triggers. Specifically, the experiment was constructed to test the claim that hard triggers induce obligatory context repair while soft triggers only induce optional repair. Domaneschi tested this prediction by presenting subjects with short stories that contained sentences with presupposition triggers in neutral contexts. The presuppositions were not a part of the common ground. After reading the stories, subjects were asked to answer questions regarding the presupposed content. Correct responses were interpreted as an indication that the content of the presupposition was processed (and maybe accommodated) by the subjects, while incorrect responses were treated as an indication that the presupposition was not processed. To study the cognitive demands that different categories of presupposition triggers place on listeners, participants were asked to keep either one or three (depending on experimental conditions) geometrical figures in their working memory. In line with Glanzberg's predictions, univariate analysis of variance showed a significant effect of the type of trigger on the processing of presuppositions, suggesting that presuppositions activated by the use of soft triggers were processed less often that presuppositions activated by hard triggers. Post hoc analysis showed three homogenous subsets of triggers: the first one includes definite descriptions and factive verbs which were processed most often; the second intermediate category consists of change of state verbs; and the third category includes iteratives and focus-sensitive particles which were least often processed.

I would like to make two comments here. The first one is about the use of the word 'processing' assumed in this paper. While the experimental procedure described above only gathered off-line data and thus was not specifically designed to elucidate the character of on-line processing of presuppositional content as an 
utterance unfolds, it nevertheless can give us information concerning whether or not the content of the presupposition is processed by the receiver. This is firstly due to the fact that in order to accommodate a presupposition, the receiver has to retrieve the content of the presupposition and place it in the mental model of the discourse. Note that we do not have to assume that a correct answer indicates the accommodation of presuppositional content in order to test Glanzberg's predictions: it is enough if we treat a correct answer as an indication that the content was processed. While this procedure does not provide information about, for example, how soon the processing of presuppositional content starts, it can give us information about whether or not the content of the presupposition is processed. As we see, Domaneschi assumes that correct answers can be treated as indications that processing of the presuppositional content occurred, while incorrect answers can be treated as an indication that processing did not occur. Of course, there is a possible scenario where the content of a presupposition is processed - i.e., recognized and retrieved, following Roberts (2015) - but the accommodation is blocked by other factors. However, the relative simplicity of the contexts used in the experimental setting greatly reduces the chances of this happening. Therefore, contrary to Domaneschi (2016), I treat correct answers as a strong indication that accommodation did in fact occur. Therefore, the experimental procedure described in section 3 can provide some evidence relevant to the following question: Are certain presuppositions processed more often than others? My second comment is about the experimental procedure itself. I believe that the experimental design of asking questions about presuppositional content in order to ascertain whether or not this content was accommodated by the receiver should be extended by introducing another variable: response time. This is due to the possibility that asking about presuppositional content could facilitate a correct answer even if the presuppositional content was not accommodated in the first place simply because the question focuses the test subject on said content; i.e., the test subject may infer the correct answer on the basis of the question. Thus, significantly longer response times could indicate that correct answers are the result of an inference process after reading the question. This is especially important when testing non-standard triggers like implicative verbs, since there are doubts about the way in which the receiver accesses the implicit information conveyed by them. ${ }^{3}$

\footnotetext{
${ }^{3}$ Self-paced reading tasks suggest that the accommodation of presuppositions occurs on-line during the reading of sentences, so additional measurements of response times may not be necessary. However, one should note that, for example, Tiemann et.al. (2011) are cautious as to whether self-paced reading tasks can give a definite answer to the question of when accommodation precisely occurs.
} 


\subsection{Reinforceability of presuppositions}

According to a hypothesis put forth by Jerry Sadock (1978), only conversational implicatures can be reinforced without causing anomalous redundancies, which means that a speaker can explicitly add a proposition that is on the level of conversational implicature to his utterance without giving the impression that he is communicating the same information twice. In a previous experiment (Włodarczyk 2019), I put this hypothesis to test using conversational implicatures and various presupposition triggers, including implicative verbs. I presented the test subjects with simple dialogues containing either a single presupposition trigger or a conversational implicature. After reading the dialogue, subjects were presented with reinforced versions in which the information which had been communicated on the implicit level was explicitly added to the dialogue. Subjects were then asked to assess, on a five-point Likert scale, the redundancy of the added information. The results suggest that conversational implicatures can be reinforced without causing anomalous redundancies, while presupposition triggers, including definite descriptions, factive verbs and change of state verbs, induce anomalous redundancies when reinforced. However, the test subjects rated implicative verbs as neutral in respect to redundancy: The explicit addition of a presupposition activated by the use of implicative verbs was not treated as a repetition of the previously available information. One way of explaining the differences in reinforceability between implicative verbs and other triggers is that the former are not accommodated as easily (or as often) as the latter. If they are not accommodated, their content is not part of the common ground and therefore is not considered a repetition of information when reinforced

In Włodarczyk 2019, I suggest that rather than treating them as a presuppositions, propositions activated by the use of implicative verbs could be understood as the default meanings of those verbs (more specifically, as world knowledge defaults; see Jaszczolt 2010). This general approach of trying to find a better category for implicative verbs is nothing new. As we already mentioned, Abbott (2000) and Karttunen (2016) have suggested that implicative verbs are better understood as activating conventional implicatures rather than presuppositions. I would argue that this particular proposal is not adequate for the following reason: While conventional implicatures are not part of what is said, they are part of the standard interpretation of sentences whose utterances give rise to them. Therefore, in my previous experimental study, on the assumption that they are conventional implicatures, they should have caused anomalous redundancies when reinforced ${ }^{4}$, but they did not. However, the framework developed by Glanzberg gives us another possibility to explain the behaviour of implicative verbs. As we remember, on Glanzberg's account, the repair process is not obligatory in regard to soft presupposition triggers, which would, on the

${ }^{4}$ This is not only my intuition; conventional implicatures are assumed to be non-reinforceable (Wayne 2019). 
assumption that implicative verbs fall into that category, explain the results that we've seen in Włodarczyk 2019. If the process of context repair is optional for presuppositions activated by the use of implicative verbs, there is a possibility that test subjects did not accommodate the presuppositional content of the implicative verbs. Therefore, when reinforced, the presuppositional content of those verbs would not have been considered as a repetition of information available before the reinforcement. If this is the case, the potential update instructions for implicative verbs is similar to that for other soft presupposition triggers, where the assertive part of the implicative verb can be processed independently from the presuppositional content. However, since my previous experiment was not designed to measure accommodation but, rather, the redundancy of information, a different experimental setting was needed in order to better explore the behaviour of implicative verbs.

\section{Experiment}

The primary goal of the experiment was to gather evidence relevant to the question of whether there are differences in the process of accommodation of presuppositions activated by the use of implicative verbs as compared to contents associated with the use of other presupposition triggers. As shown in the previous sections, according to the theoretical framework developed by Glanzberg, we can define soft presupposition triggers as triggers that induce optional context-repairs and hard presupposition triggers as inducing obligatory context-repairs. Taking into account that accommodation can be understood as a context-repairing process, we can use information about the accommodation of different triggers as evidence in regard to their classification as either hard or soft triggers. This approach is used by Domaneschi (2015) with respect to factive verbs, change of state verbs, definite descriptions, iteratives and focus-sensitive particles, confirming that iteratives and focus-sensitive particles (identified by Glanzberg as soft triggers) form a category of triggers that are processed significantly less often than definite descriptions and factive verbs (identified as hard presupposition triggers).

While Glanzberg does not provide a direct account of implicative verbs, echoassessement tests suggest that they too can be classified as soft presupposition triggers, which means that the update of the context by the assertive component of a sentence that contains an implicative verb is not dependent on the fulfillment of the instruction that tests whether the presuppositional content is part of the context. We can thus formulate our primary hypothesis for the experiment:

(H1) The processing of presuppositions associated with the use of implicative verbs is optional when presented in neutral contexts. Therefore, implicative verbs fit the description of soft presupposition triggers. 
Nevertheless, due to the fact that implicative verbs are not very well studied in experimental settings, this research also give us the opportunity to test some additional, secondary hypotheses regarding implicative verbs and other presupposition triggers. Firstly, following Laui Karttunen's suggestion that presuppositions should not be considered as forming a homogenous category, we can ask a question about the differences between various categories of triggers with respect to the ways they are processed. Specifically, with proposed the experimental procedure, we can test whether there are differences in the accommodation process of various presupposition triggers. In this connection, then, we can formulate and test the following hypothesis:

(H2) Presuppositions associated with the use of different triggers exhibit significant differences in regard to the accessibility of the information communicated on the level of presuppositions. In short, the class of triggers is heterogeneous with regard to the process of accommodation.

Furthermore, as the procedure was designed to test the accessibility of information communicated at the implicit level of the utterance, and following Włodarczyk 2019, I decided to include conversational implicatures in the experiment. Firstly, as shown in section 2.2, neither conversational implicatures nor implicative verbs induce anomalous redundancies when reinforced. I put forth the hypothesis that implicative verbs are reinforceable due to the fact that presuppositions activated by their use are accommodated less often than by other triggers. In other words, the difference in reinforceability could be due to differences in the accessibility of implicit information. Perhaps conversational implicatures are similar: They could be reinforced without inducing anomalous redundancies because the information communicated on the level of implicature is not readily available to the hearer. Conversational implicatures, construed as forming part of the implicit meaning of an utterance, are assumed to be accessed by the receiver via an inference process that is guided by a set of conversational rules. For this reason, it is probable that information communicated at the level of conversational implicature is less accessible than content activated by the use of presupposition triggers - especially triggers activating presuppositions that are assumed to have a conventional source, such as definite descriptions. This leads to the third hypothesis:

(H3) Information communicated at the level of conversational implicature is less accessible to the receiver than information communicated via the activation of a presupposition trigger.

The fourth hypothesis tested in the current study is based on the suggestion in Karttunen (2015) and Abbott (2000) that: 
(H4) Implicit information communicated via the use of implicative verbs is akin to conventional implicatures rather than presuppositions.

The fifth hypothesis is inspired by Simon's suggestion that presuppositions associated with the use of factive verbs and change of state verbs have conversational sources. While the presented experimental design does not give direct information about on-line processing of the aspects of meaning studied in the experiment, it nevertheless gives us clues about how information communicated either at the level of presupposition activated by the use of different triggers or at the level of conversational implicature is recovered and placed in the mental model of the conversation. Therefore, if some presuppositions have conversational sources, we should observe similarities in how those triggers and conversational implicatures are accessed. While acknowledging that the current experimental design cannot give a conclusive answer to this question, we can tentatively formulate our hypothesis as follows:

(H5) At least some presuppositions have conversational sources.

\subsection{Method}

\subsubsection{Participants}

Test subjects were students of the University of Szczecin. Informed consent was obtained before the experiment. All subjects were native Polish speakers.

\subsubsection{Stimuli}

The test material consisted of 36 short, written dialogues in Polish, each consisting of one sentence by person A and one sentence by person B. One of the sentences in each dialogue contained a presupposition trigger or carried a conversational implicature. The presupposition triggers chosen for the experiment were implicative verbs, factive verbs, change of state verbs and definite descriptions. The following is an example of one of the dialogues used in the experiment:

A: Anna does not regret that she went to the concert.

B: The music was fantastic.

All the presupposition triggers in the dialogues activated informative presuppositions; i.e., the content of the presuppositions was not a part of the common ground. This generated presupposition failure, which in turn required participants to update the common ground of the conversation with the presupposition via a process of accommodation. The question which was displayed after the participant had read the dialogue was designed to test whether the content of the presupposition had been accessed by the participant. For example, in (9), the question was: "Did Anna go to the concert?" Participants answered the question by pressing the ' 1 ' on a standard computer keyboard for 
'yes', '3' for 'no' answer, and '0' for 'I don't know'. In most cases, the 'yes' answer suggested that the information was accessible to the receiver, but for some utterances giving rise to conversational implicatures, the 'no' answer indicated accessibility. All dialogues in the experiment were presented in 'bare-bones' contexts: robust enough for the receiver to understand the dialogue, but as minimal as possible to reduce the influence of the context on the process of accommodation. There was one exception, as implicative verbs were presented in two environments: one neutral and one which invited accommodation. Specifically, two implicative verbs (manage and remember) were sometimes placed in sentences in which the obligation of the person carrying out specific task was emphasized. Sample dialogues are shown in Table 1. All participants were tested under the same conditions.

Table 1: Sample dialogues

\begin{tabular}{|l|l|}
\hline \multicolumn{1}{|c|}{ Type of trigger } & \multicolumn{1}{c|}{ Sample dialogue } \\
\hline Implicative verbs & $\begin{array}{l}\text { A: Jan managed to grab a glass falling from the table. } \\
\text { B: He always had good reflexes } \\
\text { Question: Did Jan try to grab a falling glass? }\end{array}$ \\
\hline $\begin{array}{l}\text { Implicative verbs } \\
\text { (second version) }\end{array}$ & $\begin{array}{l}\text { A: Wojtek remembered to buy flowers to his wife. } \\
\text { B: Oh yeah, it's her birthday today! } \\
\text { Question: Was Wojtek obligated to buy flowers for his wife? }\end{array}$ \\
\hline Factive verb & $\begin{array}{l}\text { A: From what I can see, Krzysiek regrets that he invited Wojtek to the } \\
\text { party. }\end{array}$ \\
& $\begin{array}{l}\text { B: At least it got interesting. } \\
\text { Question: Did Krzysiek invite Wojtek to the party? }\end{array}$ \\
\hline Change of state verb & $\begin{array}{l}\text { A: Basia stopped calling Radek. } \\
\text { B: She is studying for the exam now.. } \\
\text { Question: Did Basia call Radek? }\end{array}$ \\
\hline Definite Description & $\begin{array}{l}\text { A: Is Marta's husband fixing the fence? } \\
\text { B: I'll go check it. } \\
\text { Question: Does Marta have a husband? }\end{array}$ \\
\hline $\begin{array}{l}\text { Conversational } \\
\text { Implicature }\end{array}$ & $\begin{array}{l}\text { A: Where did you leave the keys? } \\
\text { B: The purse is on the dresser. } \\
\text { Question: are the keys in the purse? }\end{array}$ \\
\hline
\end{tabular}

\subsubsection{Procedures}

The study was conducted in a computer room at the University of Szczecin. Instructions were read to all participants by a research assistant while stimuli, responses and data collection were controlled by a computer program. Participants only used a keyboard during the experiment. Each test subject participated in one trial

At the beginning of the trial, the participants were presented with a sample dialogue. There were no time constraints for reading the dialogue, and test subjects were instructed to read them carefully. To display the question for the dialogue, the participants had to press a key on the keyboard. The selection of one of the three answers, which were shown alongside the question, automatically displayed the next dialogue. The first three dialogues in the experiment were used to 
familiarise the participants with the procedure and did not include the aspects of meaning mentioned above.

\subsubsection{Variables}

The independent variable in the experiment was the six types of aspects of meaning: five presupposition triggers (with implicative verbs in two variants) and conversational implicatures. There were two dependent variables: i) the average score of answers given to each category of aspect of meaning; ii) the average response time for each category of aspect of meaning.

The average score of answers was used as a criterion of the accessibility of the information communicated on the level of presupposition or conversational implicature or, as mentioned in section 2.1, as a criterion of whether information was processed. For most presupposition triggers, the 'yes' answer indicated that the test subject had processed the information. Because i) all of the presuppositions in the experiment were informative and ii) there were no contradictions between presuppositional content and previous contexts that could potentially lead to a 'no' answer even after the presupposition was processed, the 'yes' answer was treated as a sign that accommodation had taken place.

The average response time was used mainly as a possible indicator that processes other than accommodation occurred, as mentioned in section 2.2. Significantly higher response times could indicate that access to the information communicated on the level of either presupposition or conversational implicature - and thus producing a correct answer to the question - was facilitated by reading the target question and inferring the content of implicit meaning.

The average response time variable was measured automatically by the program. To reduce the influence of reading time on the measurement, since not all questions were of the same length, questions were shown in parts in such a way that the last part of the question always consisted of five words (test subjects controlled the successive display of question parts by pressing a key), and time measurement was triggered by the display of the last part of each question. All times were measured in milliseconds. The order in which the dialogues were presented was randomly determined before the test. For the measurement of the accessibility of the information communicated via different aspects, the results were coded as follows: ' 1 ' was given for answers indicating that the receiver did not have access to the information; ' 3 ' was given for answers indicating that the receiver had access to the information; '2' was given for 'I don't know'.

\subsection{Results}

One-way, within-subjects ANOVA was used to analyse the results. The answers and time measurements were analysed independently. The mean response times and standard deviations are shown in Table 2: 
Table 2: Mean and standard deviation for response times (s).

\begin{tabular}{|l|l|l|l|}
\hline Aspect of meaning & Mean & Standard deviation & $\mathrm{N}$ \\
\hline Implicative verbs & 3895 & 2076,432961384001400 & 58 \\
\hline Implicative verbs 2 & 4030 & 2009,2854655500446200 & 58 \\
\hline Factive verbs & 3362 & 2098,125824341356700 & 58 \\
\hline Change of state verbs & 3442 & 1642,079535513881400 & 58 \\
\hline Definite descriptions & 2844 & 1491,590657901510400 & 58 \\
\hline Conversational implicatures & 3182 & 1525,438124036666500 & 58 \\
\hline
\end{tabular}

The mean scores and standard deviations for the accessibility of information are shown in Table 3:

Table 3: Mean and SD for accessibility of information.

\begin{tabular}{|l|l|l|l|}
\hline Aspect of meaning & Mean & Standard deviation & N \\
\hline Implicative verbs & 2,59 & 0,314091697932237 & 58 \\
\hline Implicative verbs 2 & 2,59 & 0,275921403345393 & 58 \\
\hline Factive verbs & 2,88 & 0,207291304082610 & 58 \\
\hline Change of state verbs & 2,70 & 0,306999644807084 & 58 \\
\hline Definite descriptions & 2,97 & 0,107054397140110 & 58 \\
\hline Conversational implicatures & 2,64 & 0,265772851720099 & 58 \\
\hline
\end{tabular}

The results of the F statistic with Greenhouse-Geisser correction shows: on response time, a significant effect of the aspect of meaning $\left(\mathrm{F}_{5,285}=11,226 ; \mathrm{p}<\right.$ 0,$\left.001 ; \eta^{2}=0,165\right)$; on accessibility of information, a significant effect of the aspect of meaning $\left(\mathrm{F}_{5,285}=24,797 ; \mathrm{p}<0,001 ; \eta^{2}=0,303\right)$. To check how implicative verbs differ from other triggers and conversational implicatures, a within-subject contrast test was performed. The results of this test for answer times are shown in Table 4: 
Table 4: Within-subject contrasts for answer times.

\begin{tabular}{|c|c|c|c|c|c|}
\hline 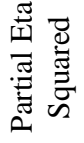 & $\stackrel{\infty}{8}$ & $\stackrel{\sim}{ \pm}$ & $\begin{array}{l}\infty \\
\infty \\
0\end{array}$ & $\vec{J}$ & $\stackrel{\overbrace{}}{\sim}$ \\
\hline$\stackrel{.00}{\bar{s}}$ & î. & $\hat{8}$ & $\stackrel{\widetilde{o}}{0}$ & 8 & 8 \\
\hline I & $\stackrel{\circ}{f}$ & \begin{tabular}{l}
$\tilde{m}$ \\
\multirow{f}{\sigma}{} \\
$\sigma$
\end{tabular} & $\begin{array}{l}\stackrel{8}{+} \\
\text { in }\end{array}$ & $\begin{array}{l}\stackrel{1}{n} \\
\stackrel{\text { a }}{2}\end{array}$ & $\begin{array}{l}\hat{\infty} \\
\text { 1 } \\
\infty \\
\infty\end{array}$ \\
\hline  & \begin{tabular}{l}
$\underset{+}{+}$ \\
\multirow{1}{*}{} \\
0 \\
0 \\
0 \\
0 \\
0
\end{tabular} & 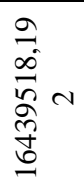 & 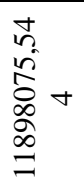 & 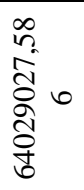 & 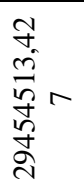 \\
\hline 㟔 & - & - & - & - & - \\
\hline 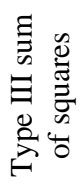 & 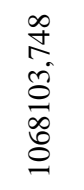 &  & 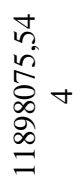 & 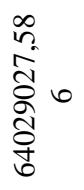 &  \\
\hline  & 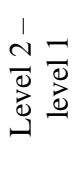 & 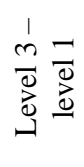 & 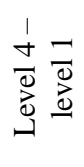 & 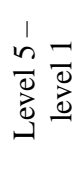 & 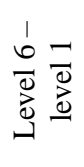 \\
\hline $\begin{array}{l}\stackrel{0}{\Xi} \\
\stackrel{0}{0}\end{array}$ & & & 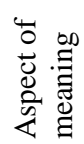 & & \\
\hline
\end{tabular}

The results of the within-subject contrast test for accessibility of information are shown in Table 5: 
Table 5: Within-subject contrasts for accessibility of information.

\begin{tabular}{|c|c|c|c|c|c|}
\hline 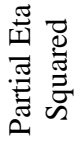 & 8 & $\begin{array}{l}\text { के } \\
\text { ?. }\end{array}$ & $\tilde{8}$ & $\frac{n}{n}$ & $\vec{\delta}$ \\
\hline$\frac{D 0}{\Delta s}$ & $\stackrel{\swarrow}{\infty}$ & 8 & 守 & 8 & $\stackrel{n}{ヘ}$ \\
\hline I & $\stackrel{\infty}{\sigma}$ & $\begin{array}{l}\stackrel{m}{m} \\
\stackrel{m}{n} \\
\stackrel{n}{n}\end{array}$ & $\begin{array}{l}\stackrel{a}{\exists} \\
\forall\end{array}$ & $\begin{array}{l}\hat{\circ} \\
\stackrel{0}{6} \\
\text { - }\end{array}$ & $\stackrel{0}{\stackrel{\sim}{I}}$ \\
\hline 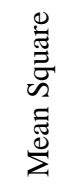 & ช̊ & 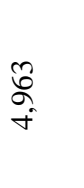 & $\overrightarrow{\mathbb{N}}$ & 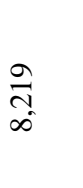 & $\stackrel{0}{=}$ \\
\hline 㟔 & - & - & - & - & - \\
\hline 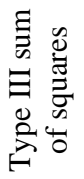 & §ิ & $\begin{array}{l}\hat{2} \\
\stackrel{\sigma}{+}\end{array}$ & $\overrightarrow{\mathbb{N}}$ & $\begin{array}{l}\stackrel{\vartheta}{\sim} \\
\infty\end{array}$ & $\underset{0}{0}$ \\
\hline 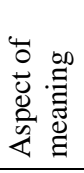 &  & 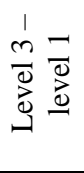 & 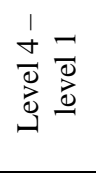 & 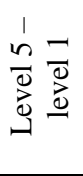 & $\begin{array}{l}1 \\
0 \\
0 \\
0 \\
0 \\
0 \\
0 \\
0\end{array}$ \\
\hline 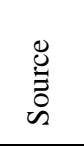 & & & 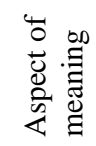 & & \\
\hline
\end{tabular}

The results of a post hoc pairwise comparison with Bonferroni correction for both parameters are shown in Appendices 1 and 2. As these results show, the aspect of meaning had a significant effect on both response times and accessibility of information. Implicative verbs in both neutral and non-neutral contexts had the longest response times: $3,895 \mathrm{~s}$ and $4,030 \mathrm{~s}$, respectively. There were no significant differences in response times between the two versions of implicative 
verbs; however, implicative verbs differed significantly from every other aspect of meaning. As for the accessibility of information, both versions of implicative verbs had the lowest score, indicating that presuppositions triggered by them were the least accessible. The differences between implicative verbs and other presuppositions were significant; however, the difference between implicative verbs and conversational implicatures was not significant. Definite descriptions also differed significantly from other aspects of meaning, including other presupposition triggers. Firstly, definite descriptions had the lowest response times, with a mean score of 2.84 seconds, differing significantly from implicative verbs and change of state verbs. Secondly, presuppositions triggered by definite descriptions had the highest mean score for accessibility of information at 2.97 , a significant difference from all other aspects.

\section{Discussion}

The main objective of the experiment was to test five hypotheses presented at the beginning of section 3 :

(H1) The processing of presuppositions associated with the use of implicative verbs is optional when presented in neutral contexts. Therefore, implicative verbs fit the description of soft presupposition triggers

(H2) Presuppositions associated with the use of different triggers exhibit significant differences in regard to the accessibility of the information communicated on the level of presuppositions. In short, the class of triggers is heterogeneous with regard to the process of accommodation.

(H3) Information communicated at the level of conversational implicature is less accessible to the receiver than information communicated via the activation of a presupposition trigger

(H4) Implicit information communicated via the use of implicative verbs is akin to conventional implicatures rather than presuppositions.

(H5) At least some presuppositions have conversational sources.

We can now discuss these hypotheses in light of the results of the experiment. As for (H1), the results seem to support the hypothesis that implicative verbs are soft presupposition triggers. As we remember, the defining characteristic of soft triggers in Glanzberg's framework is that they induce optional context-repairs, whereas hard presupposition triggers induce obligatory context-repairs. We also know that accommodation is a context-repairing mechanism, and that the 
accessibility of information in presuppositions can be used as an indication that the process of accommodation has occurred. The results of the experiment show that the accessibility of presuppositions activated by the use of implicative verbs is significantly lower than that of contents associated with the use of hard triggers (specifically, definite descriptions and factive verbs). This suggests that accommodation of presuppositions associated with implicative verbs occur less often than with hard triggers, supporting the hypothesis that they could be considered soft presupposition triggers. Additionally, response times for implicative verbs are the longest among the different categories used in the experiment. This, in turn, strongly suggests that the test subjects' access to the presupposed content of implicative verbs was (at least to some extent) facilitated by the question about the content of those presuppositions. Therefore, in normal circumstances, the process of accommodation of information activated by the use of implicative verbs could be even less accessible to the hearer. To summarize, the results of the experiment suggest a picture of implicative verbs as triggers whose presuppositions are hard to accommodate. The underlying mechanism behind this observed behaviour is still open to question.

In my view, the obtained results confirm hypothesis (H2). We observe significant differences between various triggers with respect to both accessibility and response times. First, implicative verbs differ significantly from every other category of triggers with respect to both variables. Similarly, definite descriptions and factive verbs differ significantly from all other categories of triggers with respect to accessibility of information, with the highest accessibility rating for presuppositions associated with the use of definite descriptions and the secondhighest accessibility for presuppositions triggered by factive verbs. If we look at the response times, the situation is more uniform. Definite descriptions, factive verbs and conversational implicatures do not differ significantly from each other and form a rather homogenous category. However, definite descriptions differ significantly from change of state verbs, and change of state verbs differ significantly from implicative verbs (implicative verbs with the slowest response times, and definite descriptions with fastest). One interesting aspect of these results is that two of the categories of triggers identified by Glanzberg ${ }^{5}$ as hard triggers differ significantly from each other with respect to the accessibility of their presupposed contents. This could suggest that hard triggers themselves do not form a homogenous category with respect to the obligatory character of the accommodation of what they presuppose.

Hypothesis (H3) seems to be confirmed as well by the obtained results. More specifically, gathered data support this hypothesis for categories of hard triggers. Definite descriptions and factive verbs differ significantly from conversational implicatures in term of accessibility of what they pragmatically imply. However,

\footnotetext{
$5 \quad$ Although Glanzberg does not directly identify definite descriptions as strong presupposition triggers, he considers them a type of demonstratives, which are classified as hard triggers.
} 
we do not observe significant differences between conversational implicatures and contents presupposed by utterances containing change of state verbs. The presuppositions associated with the use of implicative verbs, in turn, are less accessible than conversational implicatures.

The results of the experiment do not support hypothesis (H4). Again, presuppositions triggered by implicative verbs had the lowest score in accessibility of information. Conventional implicatures, which are not part of what is said, are still part of the conventional meaning of sentences. In light of this, if we assumed that information activated by the use of implicative verbs were a conventional implicature, it would be harder to explain why the accessibility of the information was lower than the accessibility of information communicated at the level of conversational implicature.

Finally, the results of the experiment do not lend much credence to (H5). Once again, the experimental procedure was not designed to directly address the issue of the source of presuppositions. However, factive verbs - which, as Simons suggests, have conversational sources - differed significantly from conversational implicatures in terms of the accessibility of information. Presuppositions associated with the use of change of state verbs, which constitute the second category of triggers Simons identifies as possibly having a conversational source, do not differ significantly from conversational implicatures in terms of accessibility. Interestingly, however, we also observe significant difference between both categories of presupposition triggers. These results suggest that even if presuppositions triggered by factive verbs and change of state verbs have conversational sources, there are other factors that have an impact on their accessibility.

The response time variable differentiated the results of various aspects of meaning to a lesser extent than the accessibility of information variable. We still observe two significant differences. Firstly, presuppositions triggered by implicative verbs had the highest response times. This could suggest that, as mentioned in section 2.2, the access to information conveyed by implicative verbs at the level of presupposition is facilitated by reading the target question. Secondly, the response time for presuppositions triggered by the use of definite descriptions is significantly faster than the response time for contents associated with the use of both implicative verbs and change of state verbs. This is especially interesting in light of the accessibility of information variable, according to which presuppositions of change of state verbs are the second least accessible among implied contents associated with the use of all triggers. One possible explanation of this result is that, as suggested by Domaneschi (2016: 122), the difficulty of processing presuppositional contents of change of state verbs is due to the fact that they imply a representation of temporally displaced events, which could lead to a higher processing cost. 


\section{References}

Abbott, Barbara. 2000. Presuppositions as nonassertions. Journal of pragmatics, 32(10), 1419-1437. https://doi.org/10.1016/S0378-2166(99)00108-3

Abusch, Dorit. 2002. Lexical alternatives as a source of pragmatic presuppositions. Semantics and Linguistic Theory, 12, 1-19. https://doi.org/10.3765/salt.v12i0.2867

Abusch, Dorit. 2010. Presupposition triggering from alternatives. Journal of Semantics, 27(1), 3780. https://doi.org/10.1093/jos/ffp009

Beaver, David, Geurts, Bart. 2014. Presupposition, The Stanford Encyclopedia of Philosophy, N. Zalta (ed.), URL = <https://plato.stanford.edu/archives/win2014/entries/presupposition/>. https://doi.org/10.1146/annurev-linguistics-011516-033952

Beaver, David, et al. 2017. Questions under discussion: Where information structure meets projective content. Annual Review of Linguistics, 3, 265-284.

Domaneschi, Filippo. 2016. Presuppositions and Cognitive Processes: Understanding the Information Taken for Granted. Springer. https://doi.org/10.1057/978-1-137-57942-3

Domaneschi, Filippo, Di Paola, Simone. 2018. The Processing Costs of Presupposition Accommodation. Journal of psycholinguistic research, 47(3), 483-503. https://doi.org/10.1007/s10936-017-9534-7

Von Fintel, Kai. 2008. What is presupposition accommodation, again?. Philosophical perspectives, 22(1), 137-170. https://doi.org/10.1111/j.1520-8583.2008.00144.x

Frege, Gottlob. 1892. Über Sinn und Bedeutung. Zeitschrift für Philosophie und philosophische Kritik, C: 25-50. Sense and Reference. Translation by Max Black. The Philosophical Review 57:3, 209-230. https://doi.org/10.2307/2181485

Geis, Michael, L., Zwicky, Arnold, M. 1971. On invited inferences. Linguistic inquiry, 2(4), 561566.

Jayez, Jacques, et al. 2015. Weak and strong triggers. In Florian Schwarz (ed.), Experimental perspectives on presuppositions, 173-193. New York: Springer International Publishing. https://doi.org/10.1007/978-3-319-07980-6_8

Glanzberg, Michael. 2003. Felicity and presupposition triggers. University of Michigan Workshop in Philosophy and Linguistics

Glanzberg, Michael. 2005. Presuppositions, truth values and expressing propositions. In Gerhard Preyer and Georg Peter (eds.), Contextualism in philosophy: Knowledge, meaning, and truth. Oxford: Oxford University Press.

Karttunen, Lauri. 1971. Implicative verbs. Language, 340-358. https://doi.org/10.2307/412084

Karttunen, Lauri. 2016. Presupposition: What went wrong?. Semantics and Linguistic Theory (Vol. 26), 705-731. https://doi.org/10.3765/salt.v26i0.3954

Levinson, Stephen, C. 1983. Pragmatics. New York: Cambridge University Press.

Lewis, David. 1979. Scorekeeping in a language game. In Bäuerle Rainer, Urs Egli, and Av Stechow (eds.) Semantics from different points of view, 172-187. Springer Berlin Heidelberg. https://doi.org/10.1007/978-3-642-67458-7 12

Roberts, Craige. 2015. Accommodation in a language game. In Barry Loewer, and Jonathan Schaffer (eds.) A Companion to David Lewis, 345-366. John Wiley \& Sons. https://doi.org/10.1002/9781118398593.ch22

Sadock, J. 1978. On Testing for Conversational Implicature. In Peter Cole (ed.), Syntax and Semantics Volume 9: Pragmatics, 281-298. New York: Academic Press. https://doi.org/10.1163/9789004368873_011

Schwarz, Florian. (Ed.). 2014. Experimental perspectives on presuppositions (Vol. 45). Springer.

Simons, Mandy. 2013. On the conversational basis of some presuppositions. In Marco Carapezza, Franco Lo Piparo and Alessandro Capone (eds.) Perspectives on linguistic pragmatics, 329-348. Springer International Publishing. https://doi.org/10.1007/978-3-319-01014-4 13 
Noveck, Ira, A., Sperber, Dan. 2004. Experimental pragmatics. Basingstoke: Palgrave Macmillan. https://doi.org/10.1057/9780230524125

Stalnaker, Robert. 1974. Pragmatic Presuppositions, In Milton K. Munitz and Peter K. Unger (eds.), Semantics and Philosophy. New York: New York University Press.

Stalnaker, Robert. 1998. On the representation of context. Journal of Logic, Language and Information, 7(1), 3-19. https://doi.org/10.1023/A:1008254815298

Stalnaker, Robert. 2002. Common ground. Linguistics and philosophy, 25(5), 701-721. https://doi.org/10.1023/A:1020867916902

Strawson, Peter, F. 1950. On referring. Mind, 59(235), 320-344. https://doi.org/10.1093/mind/LIX.235.320

Tiemann, Sonja, et al. 2011. Psycholinguistic evidence for presuppositions: On-line and off-line data. Proceedings of sinn and bedeutung, 15(15).

Davis, Wayne. 2019. Implicature, The Stanford Encyclopedia of Philosophy, Edward N. Zalta (ed.), $\mathrm{URL}=\langle$ https://plato.stanford.edu/archives/fall2019/entries/implicature/>.

Witek, Maciej. 2019. Accommodation in Linguistic Interaction. On the so-called triggering problem. In Piotr Stalmaszczyk (ed.), Philosophical Insights into Pragmatics, Berlin and Boston: De Gruyter, 163-192. https://doi.org/10.1515/9783110628937-009

Włodarczyk, Mateusz. 2019. Are Implicative Verbs Presupposition Triggers? Evidence from Polish. In Maciej Witek, Iwona Witczak-Plisiecka (eds.), Varieties and Dynamics of Speech Actions, 206-230. Leiden: Brill Rodopi. https://doi.org/10.1163/9789004366527_011

Appendix 1: Pairwise comparison with Bonferroni correction for response times

\begin{tabular}{|c|c|c|c|c|c|c|}
\hline \multirow[b]{2}{*}{ 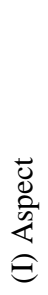 } & \multirow[b]{2}{*}{ 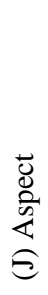 } & \multirow{2}{*}{ 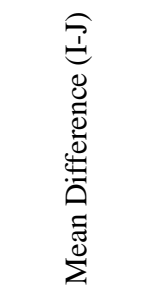 } & \multirow[b]{2}{*}{ 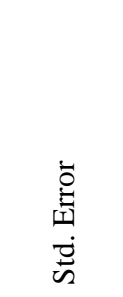 } & \multirow[b]{2}{*}{$\dot{00}$} & \multicolumn{2}{|c|}{$\begin{array}{l}95 \% \text { Confidence Interval for } \\
\text { Difference }\end{array}$} \\
\hline & & & & & Lower Bound & Upper Bound \\
\hline \multirow{5}{*}{ 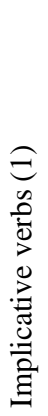 } & 2 & $-135,704$ & 203,217 & 1,000 & $-758,350$ & 486,942 \\
\hline & 3 & $532,391^{*}$ & 173,321 & 049 & 1,344 & 1063,437 \\
\hline & 4 & 452,923 & 193,295 & ,340 & $-139,324$ & 1045,170 \\
\hline & 5 & $1050,690^{*}$ & 193,408 &, 000 & 458,097 & 1643,282 \\
\hline & 6 & $712,626^{*}$ & 166,645 &, 001 & 202,035 & 1223,218 \\
\hline \multirow{4}{*}{  } & 1 & 135,704 & 203,217 & 1,000 & $-486,942$ & 758,350 \\
\hline & 3 & 668,095 & 248,653 &, 142 & $-93,766$ & 1429,955 \\
\hline & 4 & $588,627^{*}$ & 191,248 &, 048 & 2,653 & 1174,601 \\
\hline & 5 & $1186,394^{*}$ & 221,300 &, 000 & 508,343 & 1864,444 \\
\hline
\end{tabular}




\begin{tabular}{|c|c|c|c|c|c|c|}
\hline & 6 & $848,330^{*}$ & 153,495 & ,000 & 378,031 & 1318,630 \\
\hline \multirow{5}{*}{ 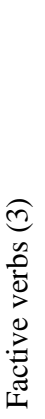 } & 1 & $-532,391^{*}$ & 173,321 & 049 & $-1063,437$ & $-1,344$ \\
\hline & 2 & $-668,095$ & 248,653 &, 142 & $-1429,955$ & 93,766 \\
\hline & 4 & $-79,468$ & 193,619 & 1,000 & $-672,708$ & 513,772 \\
\hline & 5 & 518,299 & 184,134 &, 100 & $-45,878$ & 1082,475 \\
\hline & 6 & 180,236 & 171,323 & 1,000 & $-344,689$ & 705,161 \\
\hline \multirow{5}{*}{ 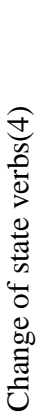 } & 1 & $-452,923$ & 193,295 & ,340 & $-1045,170$ & 139,324 \\
\hline & 2 & $-588,627^{*}$ & 191,248 & 048 & $-1174,601$ & $-2,653$ \\
\hline & 3 & 79,468 & 193,619 & 1,000 & $-513,772$ & 672,708 \\
\hline & 5 & $597,767^{*}$ & 147,890 &, 002 & 144,638 & 1050,895 \\
\hline & 6 & 259,703 & 170,273 & 1,000 & $-262,004$ & 781,411 \\
\hline \multirow{5}{*}{ 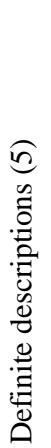 } & 1 & - & 193,408 & ,000 & $-1643,282$ & $-458,097$ \\
\hline & 2 & $\begin{array}{l}- \\
1186,394^{*}\end{array}$ & 221,300 &, 000 & $-1864,444$ & $-508,343$ \\
\hline & 3 & $-518,299$ & 184,134 &, 100 & $-1082,475$ & 45,878 \\
\hline & 4 & $-597,767^{*}$ & 147,890 & ,002 & $-1050,895$ & $-144,638$ \\
\hline & 6 & $-338,063$ & 166,891 &, 712 & $-849,409$ & 173,282 \\
\hline \multirow{5}{*}{ 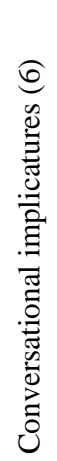 } & 1 & $-712,626^{*}$ & 166,645 & ,001 & $-1223,218$ & $-202,035$ \\
\hline & 2 & $-848,330^{*}$ & 153,495 &, 000 & $-1318,630$ & $-378,031$ \\
\hline & 3 & $-180,236$ & 171,323 & 1,000 & $-705,161$ & 344,689 \\
\hline & 4 & $-259,703$ & 170,273 & 1,000 & $-781,411$ & 262,004 \\
\hline & 5 & 338,063 & 166,891 &, 712 & $-173,282$ & 849,409 \\
\hline
\end{tabular}


*. Mean difference is significant at ,05.

Appendix 2: Pairwise comparison with Bonferroni correction for accessibility of information

\begin{tabular}{|c|c|c|c|c|c|c|}
\hline \multirow{2}{*}{ 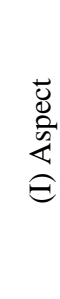 } & \multirow{2}{*}{ 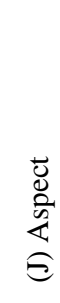 } & \multirow{2}{*}{ 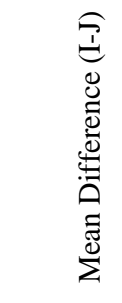 } & \multirow{2}{*}{ 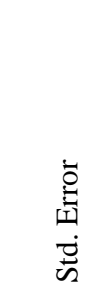 } & \multirow[b]{2}{*}{$\frac{00}{52}$} & \multicolumn{2}{|c|}{ 95\% Confidence Interval for Difference } \\
\hline & & & & & Lower Bound & Upper Bound \\
\hline \multirow{5}{*}{ 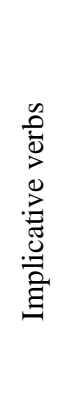 } & 2 &,- 006 & ,043 & 1,000 &,- 139 & ,127 \\
\hline & 3 &,$- 293^{*}$ & 049 & ,000 &,- 443 &,- 142 \\
\hline & 4 &,- 112 & ,055 & ,706 &,- 280 & 057 \\
\hline & 5 &,$- 376^{*}$ &, 043 & ,000 &,- 508 &,- 245 \\
\hline & 6 &,- 053 & ,048 & 1,000 &,- 202 & ,095 \\
\hline \multirow{5}{*}{ 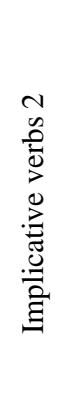 } & 1 & ,006 & ,043 & 1,000 &,- 127 & ,139 \\
\hline & 3 &,$- 287^{*}$ & ,049 & ,000 &,- 438 &,- 136 \\
\hline & 4 &,- 106 & ,056 & 933 &,- 276 & 065 \\
\hline & 5 &,$- 371^{*}$ & ,039 & ,000 &,- 489 &,- 252 \\
\hline & 6 &,- 048 & ,040 & 1,000 &,- 170 & 074 \\
\hline \multirow{5}{*}{ 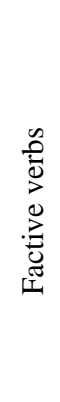 } & 1 & ,293* & 049 & ,000 & ,142 & 443 \\
\hline & 2 &, $287^{*}$ & 049 & ,000 & 136 & 438 \\
\hline & 4 &, $181^{*}$ & ,042 & ,001 & 051 & ,311 \\
\hline & 5 &,$- 084^{*}$ & 026 & ,037 &,- 165 &,- 003 \\
\hline & 6 &, $239^{*}$ & ,044 & ,000 & ,105 & ,373 \\
\hline
\end{tabular}




\begin{tabular}{|c|c|c|c|c|c|c|}
\hline \multirow{5}{*}{ 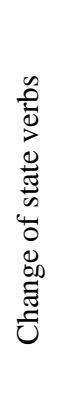 } & 1 &, 112 & 055 & ,706 &,- 057 & ,280 \\
\hline & 2 & ,106 & 056 & 933 &,- 065 & ,276 \\
\hline & 3 &,$- 181^{*}$ & 042 & ,001 &,- 311 &,- 051 \\
\hline & 5 &,$- 265^{*}$ & 042 & ,000 &,- 394 &,- 136 \\
\hline & 6 & 058 & 050 & 1,000 &,- 095 & ,211 \\
\hline \multirow{5}{*}{ 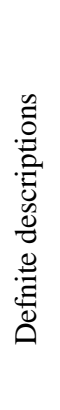 } & 1 &, $376^{*}$ & 043 & ,000 & 245 & ,508 \\
\hline & 2 &, $371^{*}$ & 039 & ,000 & ,252 & ,489 \\
\hline & 3 &, $084^{*}$ & 026 & 037 & ,003 & ,165 \\
\hline & 4 &, $265^{*}$ &, 042 & ,000 & ,136 & ,394 \\
\hline & 6 &, $323^{*}$ & 038 & ,000 & ,205 & ,441 \\
\hline \multirow{5}{*}{ 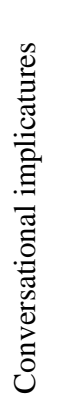 } & 1 & 053 & 048 & 1,000 &,- 095 & ,202 \\
\hline & 2 & 048 & 040 & 1,000 &,- 074 &, 170 \\
\hline & 3 &,$- 239^{*}$ &, 044 & ,000 &,- 373 &,- 105 \\
\hline & 4 &,- 058 & 050 & 1,000 &,- 211 & ,095 \\
\hline & 5 &,$- 323^{*}$ & 038 & ,000 &,- 441 &,- 205 \\
\hline & & & & & & \\
\hline
\end{tabular}

